\title{
LAS MUJERES ENTRE LA INTIMIDAD DOMÉSTICA Y EL ESPACIO PÚBLICO. LIBROS DE CUENTAS FEMENINOS Y ORDENANZAS MUNICIPALES ${ }^{1}$
}

\author{
Ma ISABEL GASCÓN UCEDA \\ Fent Història. Associació catalana d'estudis històrics
}

\author{
Fecha de recepción: enero 2012 \\ Fecha de aceptación: febrero 2012
}

El espacio doméstico ha sido tradicionalmente considerado como el espacio «natural» de las mujeres, el lugar privado en el que la sociedad de los siglos modernos pretendía recluirlas. Pero los límites entre lo público y lo privado, entendido aquí como doméstico, no se correspondían con el significado actual. En el siglo XVII, Sebastián de Covarrubias $^{2}$ asociaba privado a privación, una persona a quien se le ha excluido de oficio o dignidad. En segunda acepción, privar equivale a ser favorecido por algún señor, que le particulariza y le diferencia de los demás, a este favor recibido lo denomina privanza. Público, lo que todos saben y es notorio, lo incluye en la voz publicar,

\footnotetext{
1. Los libros de cuentas presentados en este estudio pertenecen al Archivo de la Corona de Aragón (ACA) sección Monacales; Hacienda; Ms. 684; Ms. 1984; Ms. 2052; Ms. 2487; Ms. 3391; Ms. 3397; Ms. 3398; Ms. 3401; Ms. 3431; Ms.3532; Ms. 3550; Ms. 3776; y corresponden a Isabel Despes, Valeria Dalmau, Isabel Sala, Petronila Roger, Teresa Ferragut, Jerónima Tries y Tudó, albaranes a favor de Fco. Gordeu y de Magdalena Gordèu y de Vergós, Lucrecia Dalmau, Margarida Fosalba y una relación sin nombre, de sueldos de criados y notas varias. En adelante se citarán por las siglas del archivo y el número de manuscrito. Estos libros han sido trabajados atendiendo más a la pluralidad de los asuntos que las mujeres trataban en su vida cotidiana, que a realizar un desglose pormenorizado de todos los apuntes que contienen. Las ordenanzas municipales se encuentran en el Arxiu Històric de la ciutat de Barcelona (AHCB) Registre d'Ordinacions; Sèrie 1B. IV; números 12 a 44, años 1499-1714. Se citarán por las siglas del archivo y el número de manuscrito. Para este trabajo se han utilizado únicamente aquellos aspectos de las ordenanzas municipales que guardan relación con las anotaciones privadas.

2. CovarRuBIAS, Sebastián: Tesoro de la Lengua Castellana o Española. Según la impresión de 1611, con las adiciones de Benito Reigio Noydens publicadas en la de 1674. Edición digital: Biblioteca Virtual Miguel de Cervantes, 2006.
} 
manifestar en público alguna cosa. Como señala Philippe Ariès ${ }^{3}$, durante los siglos de la Edad Moderna muchos actos de la vida privada se realizaban en público, el individuo estaba limitado y rodeado por una comunidad en la que todos se conocían y se espiaban mutuamente. Las viviendas familiares, además de ser lugares de habitación, eran también lugares de producción y lugares de consumo. En muchas ocasiones los talleres compartían el lugar de trabajo con la cocina o la sala; los compradores y vendedores entraban y salían del espacio doméstico; los aprendices o los oficiales podían vivir bajo el mismo techo que el patrón; los huéspedes, o los niños ajenos criados a pecho, comían y dormían con la familia ${ }^{4}$. La casa no era exclusivamente un lugar de residencia familiar donde protegerse de las inclemencias del tiempo o satisfacer las necesidades biológicas, ni un espacio cerrado, una clausura, en el que solo existieran las mujeres aisladas de la comunidad y los acontecimientos sociales.

Las mujeres eran el eje central y las administradoras del hogar, preparadas para el matrimonio desde su infancia aprendían a realizar las labores domésticas con independencia del lugar que ocupaban en la escala social. Unas para realizarlas posteriormente por sí mismas, otras para dirigir y supervisar al servicio. Todas para conocer la forma correcta de cumplir con sus futuras obligaciones cuando les llegara el momento de gobernar su propia casa. Las mujeres de los grupos populares, además de asumir los trabajos domésticos, ayudaban a sus padres, hermanos o maridos en sus respectivos oficios. Con el propósito de aportar unos ingresos que ayudaran a completar la precaria economía familiar, hilaban o tejían en sus domicilios para terceras personas, o realizaban tareas domésticas fuera del hogar como sirvientas de familias acomodadas. Entre las viudas, algunas gracias a los conocimientos y la experiencia laboral que habían adquirido junto a sus maridos, continuaban ejerciendo su oficio y administrando sus hogares y haciendas cuando las tenían.

Tenemos ejemplos de las actuaciones femeninas en los libros de cuentas donde reflejaban los aspectos económicos de sus vidas cotidianas. Son un tipo de documentos que solo pueden mostrarnos la realidad de un número limitado de mujeres, aquellas que además de contar sabían leer y escribir, o tenían quien lo hiciera por ellas. Lamentablemente no son muy abundantes porque tampoco lo eran las mujeres que, en una sociedad fundamentalmente iletrada, utilizaban habitualmente la lectura y la escritura. Sin embargo, hay un número suficiente para que podamos tener información sobre sus intereses personales, sus ocupaciones domésticas y sus estrategias económicas. La mayor parte de ellos se han perdido debido a su carácter de documentos privados y cotidianos. Pero son, precisamente, estas características de privacidad y cotidianeidad las que proporcionan a los manuscritos los elementos que nos permiten trascender la mera objetividad contable y la frialdad aportada por los números para entrever la intimidad de sus autoras. Cada uno de ellos refleja la personalidad y las

3. ARIÈs, Philippe: Historia de la vida privada. Del Renacimento a la Ilustración. Tomo3. Madrid, Taurus, 2000, pg. 13.

4. SARTI, Raffaella: Vida en familia. Casa, comida y vestido en la Europa Moderna. Barcelona: Crítica, 2003. 
circunstancias de la mujer que los escribe y, en ocasiones, también de las personas que les rodean. El apunte detallado de los gastos que conlleva el cuidado a los enfermos y la atención a un moribundo, las recetas de conservas o de belleza, los préstamos realizados, los censos y alquileres cobrados, los poemas anotados al margen o la contratación de sirvientes, conviven entre sus páginas proporcionándonos una rica perspectiva de su intimidad y su quehacer doméstico. Lo público y lo privado se entremezclan en unos libros pertenecientes a mujeres viudas, como Petronila Roger, o a mujeres casadas como Isabel Sala que comparte las anotaciones con su marido Bernat Sala. Él fue quien inició el libro «de recort» en 1628 en su nombre y el de sus esposas, con la intención de anotar algunas cosas «menudas», menos importantes que las que consignaba en su libro de debe y haber, evitando que se le olvidaran o se extraviaran. Isabel fue la esposa que le sobrevivió y quien continuó con sus anotaciones en solitario.

La presencia social de las mujeres en el espacio urbano, fuera de la intimidad del hogar, podemos percibirla a través de las normas y prohibiciones emanadas de las ordenanzas municipales que intentan regular la vida en común de los ciudadanos ${ }^{5}$. Unas normas generales de convivencia que coinciden en algunos puntos con los temas que ellas tratan en sus libros de cuentas, y son los que se utilizan en este trabajo. Se han agrupado en tres ámbitos generales: el espacio doméstico, la atención prestada a las personas de su entorno, y finalmente, la actividad económica.

\section{ESPACIO DOMÉSTICO}

\subsection{Recetas}

El intercambio de conocimientos femeninos se realizaba habitualmente de forma oral por lo que son pocos los recetarios de autoría femenina que se conocen ${ }^{6}$. Las madres eran las encargadas de educar y transmitir a sus hijas todos los conocimientos domésticos que iban a necesitar en su vida futura para convertirse, ellas también, en buenas esposas y madres. Las instruian en los secretos de la gran variedad de quehaceres cotidianos que requería el funcionamiento del hogar. Durante la Edad Moderna existían recetarios de diversas tipologias, unos estaban escritos por hombres y destinados a las mujeres que eran quienes, en definitiva, ponían en practica las recetas que allí se recogían, y otros los escribieron mujeres pertenecientes a los estamentos privi-

5. Para la Edad Media el tema ha sido trabajado por VINYOLES, Teresa: «La mujer Bajomedieval a través de las Ordenanzas Municipales de Barcelona» Las mujeres medievales y su ámbito jurídico. Actas de las Segundas Jornadas de Investigación Interdisciplinaria. Madrid: Universidad Autónoma, 1983. pp. 137-154.

6. Sobre recetarios femeninos ver: MARTÍNEZ CRESPO, Alicia (Ed.): Manual de mugeres en el qual se contienen muchas y diversas reçeutas muy buenas. Salamanca: Ediciones universidad, 1995; PÉREZ SAMPER, $\mathrm{M}^{\mathrm{a}}$ de los Ángeles: «Los recetarios de mujeres y para mujeres. Sobre la conservación y transmisión de los saberes domésticos en la época moderna» Cuadernos de Historia Moderna, nº 19, 1997 (monográfico: pp. 121-154); Gras I CASANOva, M. Mercè, PÉREZ SAMPER, Ma Àngels: «Els receptaris de cuina a l'època moderna» Actas Ir. Col.loqui d'Historia de l'Alimentació a la Corona d'Aragó. Lleida: Institut d'Estudis Ilerdencs, 1995. 
legiados. Estas mujeres, letradas y más alejadas de los fogones, suplieron la falta de experiencia que proporciona la práctica habitual con la receta escrita. En sus recetarios anotaban indistintamente recetas de cocina, médicas o de belleza, pero las recetas traspasaron los límites estrictos de los recetarios introduciéndose también en otras formas habituales de escritura como las cartas o los libros de cuentas.

A pesar de que la belleza era un tema por el que las mujeres de los siglos modernos tenían gran interés ya que el modelo de la época las quería de piel lisa y blanca, exenta de pecas, manchas e imperfecciones, con las mejillas sonrosadas, los dientes perfectos y el cabello rubio, estas recetas son muy escasas en los libros trabajados. Solamente dos mujeres Margarida Fosalba e Isabel Sala hacen referencia a perfumes y «aigua per la cara» para la que se necesitan:

"dos unsas de aygua de plateros y en ella hecharan tres reales en plata castellanos y si los allan en medios reales es meÿor ÿ los hecharan dentro del agua de plateros que por otro nombre la llaman agua fuerte y para aderesar esta agua que este en su punto ha de haber dos reales para mercar los polvos de litarge de plata y otras aguas que son menester para que esto se cuesga que venga a quedar en su punto» ${ }^{7}$

Es de suponer que la edad y la situacion de las mujeres que escribieron estos libros influyó en esta escasez de fórmulas de belleza. La mayor parte de ellas son piadosas mujeres - los libros proceden de un fondo monacal-y, desde un punto de vista moral, no era adecuado que usaran afeites y galas. Las casadas solo podían llevar las que les permitieran sus maridos y a las viudas les reservaban únicamente las admitidas por su estado: la soledad y la tristeza ${ }^{8}$. La belleza tenía que ser natural. Los predicadores clamaban por la falta de respeto que mostraban las mujeres a la obra de Dios, embadurnándose la cara con sustancias que podían llegar a ser nocivas para la salud o cambiando el color de sus cabellos y modificando la hechura natural de su cuerpo, mediante la utilización de cotillas y guardainfantes con los que distorsionaban y ocultaban sus figuras. Iacome Pretin ridiculiza ambas prendas en un romance escrito en $1635^{9}$

«Cuydado con guardainfante

la que a los cincuenta va

que infante guarda y no tiene

ni dientes para guardar.

En enaguas y cotilla

con arte, con magestad

una muger hecha a torno

a quien no sugetará?».

7. ACA. Ms. $3401 ;$ f. 42 .

8. REMON, Fray Alfonso: Entretenimientos y juegos honestos, y recreaciones christianas para que en todo genero de estados se recreen los sentidos sin que se estrague el alma. Madrid, 1623(I.2 Vol.2)

9. Pretin, Iacome: A los moños, enaguas, y guarda-infantes, romance escogido como entre peras. Por el maestro Iacome Pretin. Con licencia de los superiores en Barcelona en casa de Sebastián y Jayme Matevad delante de la rectoria del Pino, Año 1635. 
Entre el repertorio de recetas de cocina destacan las destinadas a la elaboración de confituras. Una ocupacion femenina en la que, excepcionalmente, se unen la utilidad, el placer y la moralidad. A la innegable utilidad practica que tienen como medio de conservacion de unos alimentos que son perecederos y estacionales, permitiendo su consumo fuera de temporada a lo largo de todo el año, se sumaba el placer que proporcionaba comer alimentos dulces y, además, era una actividad que los moralistas consideraban como una forma de honesto entretenimiento para las «señoras de calidad». Las mujeres podían entretenerse haciendo perfumes, olores y conservas, siempre que tuvieran cuidado con su uso y no cayeran en el abuso. Para evitar los perjuicios morales que podían causar se recomendaba que los olores se reservasen para las «cosas de las iglesias y los templos» y las conservas para alimentar a los enfermos y convalecientes ${ }^{10}$.

Las recetas habituales con las que preparan la comida diaria no merecen ser anotadas, son tan cotidianas que todas las conocen. Veamos, pues, cuales son algunas de las recetas excepcionales que se anotan en las páginas del libro perteneciente a Isabel Sala ${ }^{11}$ :

La conserva de flor de boratjes: Prendre tanta flor com sucre, un poch mes sucre que flor, posar un poco de aigua ab lo sucre y com es fus llansarhi la flor de la boratja picada y com te lo punt traure ho, y aixi mateix les tauletes de la boratja fins quen hi a menester manco aigua y ab dos buls te prou.

Lo eixarops de nou infusions, se fa de roses alexandrines prenent cantitat de aigua de font conforme lo eixarop que volem fer y nou voltes fer hi bollir roses alexandrines $y$ spremerles molt be $\ddot{y}$ llansarles y apres prendre aquest such posarhi mel y sucre conforme sera lo such y posarlan al foch y ferli an prendre lo punt.

Lo mel Rosat se fa de roses veres, prendre les roses y bullirles ab aigua de font, sprement be les roses y traureles such y prendre lo such y posarhi mel y ferli prendre lo punt.

Les guindes de confiter en la forma seguent, a dos lliures de guindes una y mija de sucre y una scudella de aigua.

La scursonera com sera neta y llevat lo cor posarlan ab aigua a bullir fins que sia molleta y posarlan ab una tovallola a eixugar y pesanlan com sia eixata tant sucre com scorsonera y un parell de scudelles de aigua y deixarlan ab lo eixarob fins lo sen dema.

Recepta pera fer clarea, Liura y miya de mel, una onsa de canyella, un quart de pebre $y$ un quart de gingebre a cada corter.

Recepta pera fer totes salses que sien fines y ben fetes, per a fer dos onçes y mija de salses una onsa de canyella, un quart de clavells, tres nous moscades, tres diners de pebre $y$ gingebre, un quart y mix de safra.

Recepta pera fer neulas de sucre, per a 600 neules poch mes ho manco dos liures sucre roig, quatre liures de farina molt ben passada, una liura de pinyons per a los oblias tres diners de ayguaros.

10. REMON, Op. Cit. f.90v. Sobre la opinión que les merecía a los moralistas el ocio femenino ver: GASCÓN UCEDA, M. Isabel: «Divertirse en la Edad Moderna. Necesidad social, placer individual y peligro moral» en Cuadernos de Historia Moderna. Anejos, Madrid, 2009, Anejo VIII, pp. 175-198.

11. ACA, Ms. 3401, ff. 2-5. 


\subsection{Vestidos}

La necesidad de cubrir el cuerpo para protegerlo de las inclemencias del tiempo es casi tan antigua como el ser humano ${ }^{12}$. Junto con la alimentación es una de las necesidades básicas que, a lo largo de la historia, se han ido transformando hasta convertirse en elementos de diferenciación social. El vestido permite, por una parte, la transformación individual de la figura humana en la que se remarca la propia personalidad y, por otra, la creación de imágenes colectivas que refuerzan el sentimiento de pertenencia a un grupo. La calidad de las diferentes telas y hechuras y la diversidad y utilización de los colores son un indicativo de quien es, o quien quiere parecer que es, cada persona. Es un código de comunicación visual que proporciona información sobre el sexo, la edad, el estado civil y la categoría social de quien lo lleva, algo que se tiene muy en cuenta por las autoridades municipales. Se promulgan ordenanzas para diferenciar de manera clara y sin posibilidad de error la posición en la escala social de cada individuo. No deben los «menores» de un estamento imitar con sus ropas a los «mayores» ni estos buscarán diferenciarse aumentando la riqueza de sus ropas ${ }^{13}$. De todas las confusiones posibles la más grave es la de los sexos, aunque sea en carnaval. El mejor indicador de la pervivencia de su práctica y del incumplimiento de las ordenanzas, es la reiteración a lo largo de los años de la prohibición:

«...alguna persona de qualsevol stament grau, e condicio sia vulles que sia eclesiastica, o secular no gos desfreçarse ne vestir los homes com a dones ne les dones com a homens ne de altres abits dissimulats en qualsevol manera. E qui contra fara li seran levades totes les robes ab que sera trobat desfressat e mes en la preso comuna de la ciutat. E pagara de ban doscents sols e si pagar nols pora stara pres per tant temps com los dits consellers conexeran» ${ }^{14}$.

La ropa que usaba la familia se confeccionaba habitualmente en casa, especialmente los vestidos femeninos y la ropa interior. En la mayor parte de los hogares las encargadas de llevar a cabo todas las fases de la producción eran las mujeres. Preparaban las fibras textiles, hilaban, tejían, cortaban y cosían las prendas de vestir aunque tampoco faltaban quienes encargaban a otras personas la realización de todas, o algunas de las partes, de este complejo y laborioso proceso. Isabel Sala compra lino y lo entrega a diferentes personas para su manipulación, anota pagos por hilar, devanar, tejer y lavar el lino. ${ }^{15}$ Isabel Despes compra la ropa ya confeccionada para Matheu: calzas de estameña, calcetas y escarpines de lana, y manda que le remienden unas calzas deterioradas por el uso. La ropa es un elemento imprescindible y caro, que se arregla,

12. Sobre indumentaria se pueden consultar BERNIS, C.: El traje y los tipos sociales en el Quijote, Madrid: Ediciones del Viso, 2000; De la Puerta Escribano, R.: La segunda piel. Historia del traje en España (del siglo XVI al XIX), Valencia: Biblioteca Valenciana, 2006; DESLANDRES, Yvonne: El traje imagen del hombre, Barcelona Tusquets, 1985; LAVER, James: Breve historia del traje y la moda, Madrid: Ediciones Cátedra, 2008 (undécima edición).

13. AHCB. Vol. 12, f. 5r-13v.

14. AHCB. Vol. 13, f. $41 \mathrm{v}$.

15. ACA. Ms. 3401, f. 4 v. 
se remienda y se reutiliza, se le da la vuelta a las telas que lo permiten, las distintas prendas se acortan o se alargan, se ajustan a las nuevas necesidades $\mathrm{y}$, cuando alguien fallece, se llevan a vender a la almoneda o se reparten entre otras personas ${ }^{16}$. En épocas de epidemia se prohíbe la venta de ropas «infestes de pestilencia en lo encant, ni fora aquell» ${ }^{17}$.

\section{ATENCIONES PERSONALES}

\subsection{Dotes y limosnas}

Para que una joven pueda contraer matrimonio durante la Edad Moderna es imprescindible que disponga de una dote. Sin ella no puede acceder al mercado matrimonial ni ingresar en un convento ${ }^{18}$. Las alternativas honorables que tiene a su alcance son muy escasas y las posibilidades de caer en la marginalidad y pauperización aumentan al mismo ritmo que baja su posición social. Es una cuestión que afecta de una forma tan profunda al buen funcionamiento de la sociedad, que no solo los padres intervienen y se preocupan por dotar a sus hijas. Las diferentes instituciones ciudadanas crean fondos que tienen como finalidad ayudar a las jóvenes a reunir una dote conveniente. Las cantidades que destinan algunos gremios para dotar a las doncellas casaderas se fijan en las ordenanzas y varían de uno a otro. Los pelaires crearon en 1559 un fondo de cuarenta libras para repartirlas anualmente, inicialmente eran dos las muchachas favorecidas, posteriormente el número se amplió a cuatro. Los sastres dotaban a sus hijas con veinte libras y los tintoreros con cinco. Estos últimos exigían que el padre fuera maestro examinado, que tuviera casa en la ciudad, que hubiera residido en ella de forma continua durante cinco años y que estuviera al corriente de los pagos correspondientes a su oficio. Entre las diferentes medidas adoptadas para ayudar a las familias a reunir las dotes femeninas el municipio barcelonés, autorizó la mendicidad a la familia directa: padre, madre o hermanos de la joven casadera, siempre que contasen con la licencia correspondiente, y se prohibió en los demás casos:

"Que daci avant no sie licit ni permes a persones algunes de qualsevol stament o condicio sien acaptar en la dita ciutat per fedrines a meridar si donchs no son pare, mare o jerma de la fadrina per qui acapteran e que abans de acaptar hagen haver licencia dels

16. ACA. Ms. 2487, f. 6 r, f. 20 r.

17. AHCB, vol. 12, f. 159v.

18. Ver: GASCÓN UCEDA, Ma Isabel: «Del amor y otros negocios. Los capítulos matrimoniales como fuente para el estudio de la vida cotidiana de las mujeres», Tiempos Modernos, Vol. 6, № 18, 2009. PÉREZ Molina, I. Las mujeres ante la ley en la Cataluña Moderna, Granada, Universidad de Granada, 1997. PUIG I FERRIOL, L. «Capítols matrimonials» Documents Jurídics de la Història de Catalunya, Barcelona, Generalitat de Catalunya, Departament de Justicia, 1991. pp.219-228; RIVERA GARRETAS, M. «La legislación del 'Monte delle doti' en el Quatrocento florentino» Actas de las II Jornadas de Investigación Interdisciplinaria. Las mujeres medievales y su ámbito jurídico. Madrid: Universidad Autónoma, 1983. pp. 155-173; SÁnchez PARRA, P. «Los bienes aportados al matrimonio. Evolución de la dote en la Edad Moderna» Actas de las cuartas Jornadas de Investigación Interdisciplinaria, Madrid, Universidad Autónoma de Madrid, 1994. pp. 137-148. 
honorables mossen Franci Bussot de Citges mestre Narcis Sola cirurgia y Joan Miro, pellicer ciutedans de Barcelona...» ${ }^{19}$.

Son muchas las personas particulares que ayudan a las jóvenes de sus familias, o a muchachas desconocidas, mediante donaciones directas o con la creación de fondos destinados a «causas pias para maridar doncellas» como una forma de ejercer la caridad y de obtener los consiguientes beneficios espirituales. Margarida Fosalba da como dote a su hija, la donación recibida de su marido Jaume, quien reconoce en su testamento haber gastado 300 libras de los bienes de su esposa ${ }^{20}$. También Isabel Sala promete al marido de Francesca Sulla mil libras de dote «Es li degut mil liures que de mos bens li tinch promesos y feta donatio...» la cantidad se paga en dos partes, la primera, de quinientas libras, mediante un cargo a su cuenta en «lo banc de la ciutat»" ${ }^{21}$. Además a Francesca se le restituye el censal sobre el marquesado de Pallars que su «padre y suegro» le había dado como dote y le conceden uno nuevo sobre la baronía de Orcau. La ápoca que se firma finalmente asciende a dos mil cincuenta libras «Con poliza de micer B. Sala mon marit» ${ }^{22}$. Petronila Roger, cumpliendo con el mandato testamentario de Batista Oliver, anota en su libro el pago de cien libras a la Sra. Mariangela Oliver, medio hermana suya, por constitucion de matrimonio ${ }^{23}$. También Teresa Farragut anota las dotes familiares que se pagan siempre a los maridos. Ellos serán quienes las administren y disfruten de los beneficios que puedan generar, salvo que en los capítulos matrimoniales haya alguna cláusula explicita que determine como deben gestionarse dichos bienes. Por otra parte, esas dotes garantizan a las mujeres la recuperación de los bienes en caso de que el matrimonio se disuelva. La causa más frecuente de disolución es el fallecimiento del marido.

El ejercicio de la caridad se considera una virtud inherente a la condición femenina. A las mujeres les corresponde atender a los menesterosos y velar por que las jovenes puedan mantener su virtud. La caridad es una forma de ayuda material hacia los indigentes y de ayuda espiritual, para sí mismas y para sus familias. Aunque la consideración que la pobreza tiene durante estos siglos experimenta una transformación que lleva a los pobres a ser considerados unos vagos, responsables en buena medida de sus circunstacias por su ociosidad, la caridad sigue siendo el mejor medio por el que las personas privilegiadas pueden redimir sus pecados y la mejor forma de trabajar en esta vida por el descanso eterno de sus almas. Algunas de las propietarias de estos libros de cuentas, además de hacer donativos a instituciones de beneficencia como la Pia Almoina, o de instituir censales, como hace Valeria Dalmau ${ }^{24}$ a favor del monasterio de Valdonsella, ayudan a otras mujeres ya sea de forma ocasional o mediante la concesión

19. AHCB. Vol. 13, f. 42v-45r.

20. ACA. Ms. 3550 , f. 99 r.

21. ACA. Ms. 3401 , f. 62 r.

22. Id. f. $63 \mathrm{v}$.

23. ACA. Ms. 3776.

24. ACA. Ms. 3397. 
de pensiones anuales. Teresa Ferragut dejó en 1728, un censal a la Señora Catarina Sala y Vidal de 220 libras de pension ${ }^{25}$. Hieronima Pich ${ }^{26}$, viuda de Maurisi Pich cotoner, recibió una libra y dieciseis sueldos, por dos pensiones correspondientes a los años 1645 y 1646, también Marianna Mundi ${ }^{27}$ recibió una cantidad anual.

El municipio asiste a los necesitados y permite el ejercicio de la mendicidad a los ciegos, los tullidos, o a los pobres que tengan más de dos hijos, y que obtengan la licencia correspondiente. Una licencia que no pude ser vendida, prestada, ni falsificada bajo pena de «esser escobat». Tampoco se puede pedir caridad con niños que no sean hijos propios y se prohíbe que las mujeres lleven la cara cubierta. Los vagos y mendigos que llegan de fuera son expulsados de la ciudad al cabo de tres días ${ }^{28}$. Los niños merecen una atención especial, con el fin de socorrerlos, y socializarlos correctamente, se ordena que si alguien:

«sebra algun infant o infanta en la dita ciutat que sie orfe o de persona que nol pusca proveyr ab que sie de edat ques sapia vestir e despullar vagen al honorable en Pere Guerau mercader qui sta al carrer Condal de la dita ciutat lo qual aquestes coses per la ciutat es elegit car aquell los provehira de menjar e beure vestir e calsar els fara ensenyar bon offici» ${ }^{29}$

Con la intención de erradicar la mendicidad y la holgazaneria de las calles de la ciudad, en 1633, se hace pública mediante un pregón, la ordenanza que obliga a todos los pobres a recogerse en el Hospital de Nuestra Señora de la Misericordia. Los que estén en condiciones de trabajar se pondrán bajo las ordenes de un amo, para servir o aprender un oficio y serán supervisados por los administradores. Los imposibilitados se atenderán y alimentarán en la forma que se considere más conveniente para ellos $\mathrm{y}$, para preservar la virtud de las jóvenes, todos aquellos que sepan que una mujer de mala vida tiene a su servicio una moza por criada, tendrán la obligacion de recogerla en dicho Hospital.

La situacion económica en que quedaban las mujeres al enviudar variaba, lógicamente, dependiendo de cual fuera su posición social, muchas de las que pertenecían a los estamentos inferiores al fallecer su marido veían acrecentada su pobreza y desamparo y pasaban a engrosar el número de pobres vergonyants ${ }^{30}$ aquellos que necesitaban

25. ACA. Ms. 3391.

26. ACA. Ms. 3397, 37v.

27. Id., f. $143 \mathrm{v}$.

28. AHCB.Vol.13, ff42v-45r.

29. Id.

30. Sobre pobreza en Barcelona ver los trabajos de CARBONELL, Montserrat: Pobresa i estratègies de supervivència a Barcelona a la segona meitat del segle XVIII (Les acollides a la Casa de la Misericòrdia i el Mont de Pietat de Ntra. Sra. de la Esperanza), Barcelona: Universitat de Barcelona, 1992, y Sobreviure a Barcelona: Dones, pobresa i assistència al segle XVIII, Vic: Eumo, 1997; FLORENSA I SOLER, Nuria: «L'assistència social i l'aportació econòmica del municipi barceloní al segle XVII envers malalts, prostitutes, pobres vagabunds, belitres i bergants» El temps del Consell de Cent, II. La persistència institucional segles XV-XVII (Quaderns d'Història $\mathrm{n}^{\circ}$ 5) Barcelona: Institut de Cultura, Arxiu Històric de la Ciutat, 2001. 
la asistencia que proporcionaban las instituciones religiosas y civiles, municipales o privadas, para poder sobrevivir. Las ordenanzas diferenciaban entre pobres y vagos, a estos últimos no se les permitía pedir porque:

"leven les caritats a aquells e aquelles qui no han forma de sostenir lur miserable vida los quals per gran pobresa malaltia e en atre manera son merexedors haver y rebre dites almoynes de la qual cosa provenen molts mals e inconvenients... $\rangle^{31}$

Como estrategia de subsistencia algunas mujeres traspasaban la frágil línea divisoria que las separaba de la marginalidad y la delincuencia, unas vivían amancebadas y otras ejercían la prostitución. En ambos casos, la cantidad y la reiteracion de las ordenanzas a lo largo de los años en las que se prohibía la cohabitación y se trataba de regular y limitar el ejercicio de la prostitución, nos habla de la importancia y la extension de unas practicas que la normativas, ya fueran civiles o religiosas, no lograban erradicar de la sociedad.

\subsection{El cuidado de los enfermos}

Como ya se ha dicho anteriormente en los manuales dedicados exclusivamente a recetas convivían las que se destinaban a la alimentación con las dedicadas a la belleza y al mantenimiento de la salud en una interrelación que nos recuerda al concepto moderno en el que también la dieta y el mantenimiento de un buen aspecto físico están asociados al disfrute de una buena salud. Durante el Antiguo Régimen en una sociedad en la que la presencia del médico era escasa, sobre todo fuera de las ciudades, las mujeres eran quienes atendían las dolencias más comunes del grupo familiar. Una de las características propias de la medicina de la época era la utilización habitual de purgas y sangrías para combatir la enfermedad y expulsar los malos humores ${ }^{32}$. Aunque no siempre fuera lo más conveniente para que el enfermo recobrara la salud, estaba presente en la mayoría de los tratamientos y las mujeres debían conocer al menos las formas más simples de elaboración y administración de purgantes. En la ultima página del manuscrito de Mariana Jaumató ${ }^{33}$ se hace referencia a una «Medicina per anar de cos» para cuya preparacion se requiere:

«1 lliura de mel, 1 oz. Zarzaparrilla, 1 os de senat picat, 4 diners de clauells picats, 2 diners de matafaluga picadas, $1 \mathrm{oz}$. de sucra fi. Tot se te de mesclat ab una casola nova sens coure i prendran dos cullaradas cada mati».

Además recomienda comer «rostit y beure bon vi».

La enfermedad más terrible y temida de estos siglos es la peste. En el libro de albaranes de Francisco y Magdalena Gordeu i de Vergós $^{34}$ se anota una receta para

31. AHCB. Vol. 13, ff. 42v-45r.

32. CABRÉ, Montserrat: Sanadoras, matronas y médicas en Europa, siglos XII-XX, Barcelona: Icaria, 2001; CARdoner i Planas, Antoni: Història de la Medicina a la Corona d'Aragó (1162-1479). Barcelona: Editorial Scientia, 1973; LAín ENTRALGO, Pedro: Historia de la medicina. Barcelona: Salvat, 1978.

33. ACA. Ms. 684; s/n.

34. ACA; Ms. 3398 , f.2r. 
combatirla, obtenida de la narración de un suceso ocurrido un siglo antes. En él se responsabiliza a los franceses de la introducción de la peste en Génova y el milanesado, mediante estratagemas como infectar ramos de flores o las aldabas de las puertas con las landres secas previamente molidas. El remedio que utilizaban los franceses, para que no les afectase a ellos, consistía en mezclar entre otros ingredientes: piedra assufar, incienso, corteza de naranja agria seca, granos del fruto del laurel, nuez moscada, raíces de verbena y gengibre y hojas de hierba de Santa María molidos, poner una parte del preparado en un saquito color de grana y llevarlo al lado del corazón.

Desde el poder municipal, se dictan ordenanzas encaminadas a paliar sus terribles efectos y a frenar su expansión. Se obliga a limpiar las calles, se prohibe la entrada en la ciudad a las personas procedentes de los lugares infectados y se expulsa con sus pertenencias a todos aquellos que hayan llegado de esas poblaciones. Los médicos son obligados a prestar asistencia a los enfermos ${ }^{35}$. En 1652, las personas contagiadas que no pueden ser atendidas en sus casas, se trasladan a diversos conventos donde son asistidos por personas de su mismo sexo: las mujeres a San Francisco de Paula, los pobres al convento de Jesús y los ricos al de San Agustín. Estos últimos han de llevarse la cama, el ajuar necesario y pagar por su cuenta a los médicos y enfermeros que les atienden ${ }^{36}$. Además de las medidas higiénicas y sanitarias adoptadas se solicita también la intercesión divina mediante la celebración de procesiones por las calles de la ciudad ${ }^{37}$.

Isabel Despes ${ }^{38}$ anota cuidadosamente los gastos extraordinarios que ocasiona la enfermedad del mestre Mateu en la alimentación y las atenciones sanitarias. Obsequia al médico que le visitó sin cobrar en efectivo por sus servicios con «un parell de capons y una dotsena de magranes grosses» y una toca «a la castellana» para su esposa. El barbero es el encargado de practicar las sangrías al enfermo y un grupo de mujeres ayudan a Isabel a tener dispuestas las toallas y las sábanas que se necesitan para atenderlo adecuadamente, y a velarlo durante la noche. La «buena muerte» debe de encontrar a la persona agonizante en la cama y asistida por sus parientes, o por otras personas que le acompañen espiritualmente en su tránsito final. No se cuida únicamente al cuerpo enfermo, también es necesario atender a su bienestar espiritual. Las prácticas devocionales de la Edad Moderna conceden una extraordinaria importancia a las indulgencias para acortar el tiempo de permanencia de las almas en el Purgatorio, Isabel paga cuatro sueldos por una Bula de la Cruzada que le proporcione a Mateu una indulgencia plenaria. En las páginas de estos libros también está presente otra de las formas habituales de ayuda espiritual a las personas fallecidas: los pagos de misas en memoria de los familares difuntos.

35. AHCB. Vol. 13, f.113r.; Vol. 17, f. 179v.

36. AHCB. Vol. 33, f. 18v-19v.

37. Id., f.113v.

38. ACA. Ms. 2487; f. 6r-7 r. 


\subsection{Entierros}

El final de la vida, el tránsito de vivos y difuntos a una nueva realidad, se plasma mediante una serie de ceremonias y rituales que conllevan numerosos gastos. Unas veces se anotan en los libros de cuentas de forma minuciosa y detallada, otras de forma más somera o, incluso, en papeles sueltos intercalados entre sus páginas. Las honras fúnebres con las que se despide a una persona de esta vida, son un acto social de una importancia tan relevante para el mantenimiento del prestigio familiar como la celebracion de un matrimonio ${ }^{39}$. Las familias deben dar a la persona fallecida un entierro adecuado a la posición social que tenía en vida. Su círculo de amistades y sus redes de influencia se harán patentes en el número y la categoría de las personas que asistan, o no, a los ritos que acompañan sus últimos momentos en la tierra. Se anotan los gastos de todos los detalles: los pregones, la caja y la fosa, el descenso a la sepultura, la comida funebre o las ropas para el duelo. ${ }^{40} \mathrm{~A}$ través de ellos podemos seguir el proceso desde el momento de ataviar el cuerpo y exponerlo en la cama de entierro, entre cortinas negras, rodeado de brandones y hachas para que pueda ser debidamente despedido por quienes le conocieron, hasta que el difunto llegue al lugar de su descanso definitivo acompañado por el cortejo funebre. Las ordenanzas municipales insisten a lo largo de los años en la obligatoriedad de que sean exclusivamente los hombres y mujeres internos en el Hospital de la Misericordia quienes participen vestidos con largas túnicas y llevando los cuévanos de pan para repartir entre los pobres, prohibiendo que se alquilen los servicios de otras personas ${ }^{41}$.

\section{ACTIVIDAD ECONÓMICA}

Cuando enviudaban, las mujeres procuraban seguir manteniendo los oficios de sus maridos mientras les era posible, cosa que no siempre conseguían ${ }^{42}$. Algunas de aquellas que disfrutaban de mejor situación económica continuaron con las actividades

39. ARIÈs, P.: Historia de la muerte en Occidente: desde la Edad Media hasta nuestros días. Barcelona: El Acantilado, 2000; PASCUA SÁNCHEZ, Ma José de la: «Desde la vida para la muerte: Testamento barroco y religiosidad femenina» en: Nueva lectura de la mujer: crítica histórica, Málaga: Atenea, S.L. 1995.

MUIR, Edgard: Fiesta y rito en la Europa moderna, Madrid: Editorial Complutense, 2001.

40. ACA. Ms. 2487, Ms. 3776, Ms. 3391.

41. AHCB. Vol. 21, f.52r i ss.; Vol. 25, f. 3r, f. 156r.

42. Sobre el trabajo femenino en la Barcelona Moderna consultar entre otros los trabajos de CARBONELL M.: «El treball de les dones a la Catalunya Moderna», en NASH, M. (Ed.): Més ellà del silenci: les dones a la història de Catalunya, Barcelona: Generalitat de Catalunya, 1988 p.115-128; VICENTE, Marta: «Mujeres artesanas en la Barcelona Moderna», AA.VV.: Las mujeres en el Antiguo Régimen: imagen y realidad, Barcelona: Icaria Editorial, 1994, p.59-90; VICENTE, M.: ««Comerciar en femenino». La identidad de las empresarias en la Barcelona del siglo XVIII», comunicación presentada al XIII Coloquio Internacional de la Asociación Española de Investigación de Historia de las Mujeres, Barcelona, 19-21 de octubre, 2006, Edición CD-Rom. Ver también CARBONELL, Montserrat: «Trabajo femenino y economías familiares» en Morant, I. (Dir.) Historia de las mujeres en España y América Latina II. El mundo Moderno, Madrid: Cátedra, 2005. 
económicas y financieras familiares. En ocasiones estas actividades habían sido previamente compartidas, recordemos a Isabel Sala, otras daban comienzo a una nueva etapa como indica Teresa Ferragut al iniciar en 1693 su «Llibre de notas y rebudas del que pago jo Teresa Ferragut vidua per los gastos que se offerexen per la casa del quondan Salvador Ferragut, sastre, mon marit» ${ }^{43}$. Concesiones de préstamos, alquileres, compras y ventas de inmuebles o de bienes muebles y litigios por propiedades familiares son algunas de las cuestiones a las que estas mujeres dedicaron su tiempo y energías, unas veces por la fuerza y otras con gusto por la actividad. Isabel Sala actúa como intermediaria en la compra y la venta de ropa y joyas por orden de terceras personas, en cuyo nombre realiza los cobros y los pagos

En algunos casos, como sucede con el manuscrito clasificado con el nombre de $\mathrm{D}^{\mathrm{a}}$ Mariana Jaumató y Mendoça, los apuntes corresponden a varias generaciones y son esencialmente de carácter económico: las pensiones pagadas por la familia al monasterio de San Agustín de Barcelona entre los años 1630 y 1709, los gastos derivados de la compra y el acondicionamiento de unas casas en el carrer dels Bous, y el cobro de las rentas que generaba el alquiler de viviendas. Pero, intercaladas entre los números, con treinta años de diferencia, se registran los nacimientos de dos niños. En el segundo alumbramiento, incluso se anota la duración del parto:

"Als vuit de setembre de 1652 día de Nostra Sora. desde els tres quarts de las vuitoras fins a las vuit oras de matinada (...) fout nat Ramón Francisco Rafael Jaumató, fill de Ramón Jaumato, valluter y Marianna muller sua, fou bateiat en St. Pere de las Puellas, foren Padrins Raphel Garau, retersedor de seda y fadrina Teresa Costa, vallutera» ${ }^{44}$.

Hasta mediados del setecientos no tuvo lugar en Barcelona una incipiente formalizacion de los servicios crediticios. En 1751 se creó el Mont de Pietat de Nostra Senyora de l'Esperanza i Salvació de les Animes de Barcelona ${ }^{45}$. Durante los siglos anteriores fue una práctica habitual la solicitud de préstamos a particulares cuando la situación económica familiar lo requería, dejando en prenda algún objeto como garantía de la devolución del capital en el plazo acordado. Estos mecanismos de crédito informal permitían acceder a productos de primera necesidad, pagar los alquileres o afrontar situaciones imprevistas. El valor de las prendas dejadas en depósito solían estar en relación con el monto del prestamo solicitado y con la previsible solvencia de la persona que lo solicitaba. Cecilia Vallmajor y Darlet, casada con el cirujano micer Vilamajor, le deja a Isabel Sala ${ }^{46}$ el 17 de noviembre de 1640, como garantía de un prestamo de veinte reales, una cortina bordada. Maria Joffreu le pide en 1623 diez libras, con el consentimiento de su marido, para pagar el alquiler de su casa y deja en prenda un anillo de oro con un diamante cuadrado pequeño. Dorotea Sarrovira, monja y priora del

43. ACA. Ms. 3391.

44. ACA, Ms. 684, fols. 24 y 25.

45. Ver CARBonell I ESTELler, Montserrat: Sobreviure a Barcelona. Dones, pobresa i assistència al segle XVIII. Vic: Eumo Editorial, 1997, pp.171-172.

46. ACA; Ms. 3401, f.8v; f.54v; f.65v; hoja intercalada entre las páginas 85-86. 
Monestir de Santa Clara, le solicita cincuenta libras. En este caso la palabra de la priora es suficiente como garantía de devolución pero, en ocasiones extremas, las personas se ven obligadas a empeñar algunos objetos que les son necesarios para la realizacion de sus trabajos o, incluso, sus propios hogares. La partera María de Areny, hija de Caterina Llertes, segunda suegra de Isabel, le pide prestadas veinticinco libras por las que le deja en prenda unos candelabros de plata que utiliza en el ejercicio de su profesión. En 1727 Teresa Ferragut ${ }^{47}$ presta al carpintero Francisco Figueró cincuenta libras, la devolucion queda garantizada por la casa en la que habita y todos sus bienes en general, incluidas las mejoras que pueda hacer, el plazo convenido para la devolución es de tres años; idénticas condiciones se aplican al crédito que concede a Francisco Mauri, trajinero y molinero, el mismo año. Andreu Sant Roma recibe doscientas diez libras, al ocho por ciento de interés, pagaderas a razón de un real de a ocho cada mes, en esta ocasión el deudor no empeña sus bienes porque cuenta con el respaldo de dos avalistas: Francisco Raimundo y Jaume Baro.

Las deudas contraidas no expiran con el fallecimiento de los deudores, se transmiten a los herederos y son ellos quienes deben responder de los compromisos previamente adquiridos, o pactar con los prestamistas otras condiciones mas acordes con la nueva situacion. No importa cual sea el grado de parentesco existente entre ambas partes. El librero Francesc Menescal asume la deuda contraida por su padre con Isabel Sala. Entre las cuñadas Theresa Cardona y Osest y Teresa Ferragut, se establece una concordia por la cual será el sobrino, hijo de su hermano, quien pague la deuda de su padre, a plazos y en especies: aceite, garbanzos, trigo y tocino ${ }^{48}$. No se deja ninguna cuestión sin anotar, ninguna deuda se confia a la memoria. En un apunte en el que Isabel Sala hace referencia a su sobrino, Phelip Seix y de Gomar, añade un papel suelto, sujeto con un alfiler para que no se pierda, a la hoja en la que se desglosan sus gastos haciendo constar que, además de los anotados en el libro mayor de debe y haber, en el que se asientan la partidas más importantes de la contabilidad familiar, su sobrino le debe a su marido el haberlo mantenido durante muchos años dándole casa, comida, bebida, calzado y vestido.

El control de los censales, los pagos a los procuradores, las cartas de débito por rentas de las que son acreedoras, las ápocas, las transacciones económicas con la banca o la taula de canvi de Barcelona ${ }^{49}$, la intermediacion comercial o financiera, son actividades que se reflejan con frecuencia en estos libros de cuentas femeninos «es li degut ha 20 de janer 1620 rebi de contans trenta sinch lliures les quals li he de portar a ganancia ab los meus cambis conste ab un albara que te meu. 35 lliures ${ }^{50}$. Estas mujeres hacen trabajar su dinero, lo mueven y negocian con él, no se limitan a disfrutar

47. ACA; Ms. 3391, f.42r; f.46r.

48. ACA. Ms. 3391, f. 79r.

49. La taula de cambi era una institución que funcionó en Barcelona entre los siglos XV y XVIII con la finalidad de realizar operaciones de cambio y depósitos de moneda. Isabel Sala trabaja también con el banco de Alexandre y Hieronim Moxo.

50. ACA. Ms. 3401, f.12 r. 
de sus rentas de una forma pasiva, conformándose con los réditos que les proporcionan sus posesiones. Están inmersas en los circuitos financieros del momento con la intención de aumentar sus capitales, de la misma forma que están presentes en el mercado inmobiliario. La compra-venta de casas y tierras, el alquiler, las reparaciones y el mantenimiento de los edificios forman parte de sus actividades mercantiles. En una sociedad en la que la riqueza y la prosperidad, económica y social, proceden de la posesión de la tierra ellas pleitean por mantener sus posesiones y reclaman sus derechos de herencia ante los tribunales de justicia ${ }^{51}$.

\subsection{El trabajo femenino}

Uno de los trabajos más frecuentes realizados por las mujeres en la Edad Moderna era el del servicio doméstico, una actividad para la que estaban suficientemente capacitadas y que les permitía ayudar a la economía familiar, de forma habitual o esporádica; reunir un capital que fuera suficiente para obtener una dote, o bien ganarse la vida de forma permanente. En el caso de las muchachas más jóvenes, las que entraban a servir en una casa desde niñas, lo más usual era convenir un salario entre el amo y el padre o el tutor que se pagaba en concepto de dote cuando ella salía de la casa para contraer matrimonio. Durante el tiempo que la muchacha permanecía sirviendo en la casa trabajaba por el vestido, la comida y el techo. Las mujeres mayores percibían su salario regularmente, de acuerdo con las condiciones que hubieran pactado "a sis de juliol 1599 entra en casa madona Puig per dona de cambra guanya a rao de deu lliures lany. Ha stat un mes». ${ }^{52}$ En ocasiones el pago no es monetario, se efectua en especies con prendas de vestir: "Comensa destar en ma casa Joana Caball a 22 de Juliol 1602, guania una gonela de burell... dos camises... dos capells $i$ unes calses ${ }^{53}$. Isabel Sala anota en su libro «de recort» abonos que se registran también en otros documentos contables. Quiere tener todas las cuentas claras y controladas, que no pueda haber olvidos o errores: "li es degut dos anys y mix de soldada a stat en ma casa que, a rao de deu liures lo any... li fas nota en lo libre porte a part de soldada ... vintysinch liures» ${ }^{54}$.

De la misma forma que se anotan cuidadosamente los salarios se registran los gastos y las entradas y salidas del servicio causadas por las enfermedades. Su ausencia también afecta al funcionamiento y la organización de la casa. Valentina «torna a estar en casa lo dia de Nadal guanya a rao sis lliures lany de 1599, a 10 de janer ses en malaltia ${ }^{55}$ los gastos de su enfermedad ascienden a veintitres sueldos, retorna al servicio el dos de febrero, día de la Candelaria, y lo abandona definitivamente el dos de julio de 1599 .

\footnotetext{
51. ACA. Ms. 2052; Ms. 2487.

52. ACA. Ms.3532; f.s/n.

53. ACA. Ms.3532, s/n.

54. ACA. Ms. 3401, f.87.

55. ACA. Ms.3532, s/n.
} 
Entre los pagos al personal son destacables los que están relacionados con la infancia, los tutores ${ }^{56} \mathrm{y}$, muy especialmente, las amas de cría. Un colectivo privilegiado dentro de las mujeres que realizaban trabajos domésticos. Se pensaba que las características físicas y morales de las nodrizas se transmitían al lactante a través de la leche por lo que su elección requería una cuidadosa selección por parte de los padres. Además de garantizar la supervivencia física del recién nacido, en una sociedad en la que la mortalidad infantil era elevadísima, había que cuidar su futura calidad humana. Se creía que las relaciones sexuales alteraban las propiedades de la leche materna, así pues, la mejor forma de garantizar que la nodriza estuviera bien alimentada, que no bebiera y que no mantuviera relaciones sexuales era que viviera en la misma casa que el lactante ${ }^{57}$. La utilización de leche de animal estaba desaconsejada por los riesgos sanitarios que entrañaba y el posible embrutecimiento de los niños. Paolo de Certaldo sostenía que si un lactante se alimentaba con leche de animal, no tendría una inteligencia normal y hasta su apariencia física sería la de un retrasado mental ${ }^{58}$.

Para las mujeres pobres el amamantar a los hijos de los estamentos privilegiados constituía una buena fuente de ingresos, eran las que percibían los mejores salarios entre los diversos grupos femeninos dedicados al servicio doméstico. En 1602 Antonia Sabatera $^{59}$ cobró veinte libras anuales, el doble que la mujer mejor pagada de la casa. Para que la nodriza pudiera aceptar el trabajo se requería la conformidad del marido puesto que debería abstenerse de mantener relaciones sexuales con su mujer mientras durase el periodo de lactancia. En muchas ocasiones era él quien percibía por adelantado una parte del salario que le correspondía a su mujer, algo que también sucedía en otros grupos laborales. Las mujeres no siempre cobraban directamente por su trabajo. Domingo Ferran, sastre cobró el 26 de enero de 1626 «per mans y bestreses de feyna feta per sa muller setse lliures ${ }^{60}$.

Pocas referencias se tienen sobre el trabajo doméstico en las ordenanzas municipales, unicamente se visibiliza cuando se realiza en el espacio comunitario ya sea para prohibirlo como sucede con la colada, puesto que no se permite «ensabonar o rentar bugades o altres draps ni fer altres inmundicies en les places, abeuradors e fonts de la dita ciutat... sots ban de X sous ... ${ }^{61}$ ni tampoco $"$ stendre draps, robes, bugades ... sots

56. ACA, Ms.3776.

57. BAU, Andrea María: «Los cuidados del recién nacido en España a través de la teoría médica (siglos XIII a XVI)» en GonZALEZ DE FAUVE, Ma Estela (Coord.): Medicina y sociedad: curar y sanar en la España de los siglos XIII al XVI. Buenos Aires: Instituto de historia de España «Claudio SánchezAlbornóz» Universidad de Buenos Aires, 1996; Damián Carbón: Libro del arte de las comadres o madrinas y del regimiento de las preñadas y paridas y de los niños. Impresa por Hernando de Cansoles en Palma de Mallorca, 1541. Edición de Daniel García Gutiérrez, Anubar Ediciones, Textos medievales, 93, Zaragoza, 2000.

58. Citado por BAU, Op. Cit., p. 192.

59. ACA, Ms. 3532, f. s/n, r.

60. ACA. Ms. 3401, f. 62.

61. AHCB, Vol. 13, f.155v. 
ban de XX sous» en las torres y murallas de la ciudad o, por el contrario, para obligar a su cumplimiento como hemos visto anteriormente en el caso de la limpieza de las calles para frenar la expansión de las enfermedades.

Durante los siglos de la Edad Moderna vemos a las mujeres de Barcelona en las calles y plazas de la ciudad paseando, asistiendo a la iglesia o de visita, trabajando como compradoras, vendedoras, revendedoras, hostaleras, artesanas o prostitutas. La información que nos llega a través de las Ordenanzas Municipales habla de hombres y mujeres dedicados a la venta y la reventa de productos alimenticios, de los lugares que unos y otros debían ocupar, de las tareas que cada uno de ellos debía realizar y de los diferentes horarios que tenían que cumplir para no generar confusión y engaño entre los compradores ${ }^{62}$. En 1636 se publica una ordenanza que favorece el trabajo femenino. Por primera vez, se permite que las mujeres puedan vender las labores textiles hechas por ellas mismas, independientemente de su estado civil, con la condición de que no puedan tener tienda abierta.

"... sie licit y permes a qualsevol dona de qualsevol stament o condicio sie, ara sie casada ara no, o sie viuda, fer de sas mans proprias filampuas y resillo empero de fil de canem o lli, vetas, tasfatanas, botons, brodar golillas y mitjas de agulla de seda o de altra qualsevol specie y vendrer o fer vendrer aquelles per la ciutat, en lo encant publich o plassas publicas ab que no puguen tenir botiga uberta per vendre dites cosas com tenirla sols toque a les confrarias y personas examinades... $\rangle^{63}$

Cincuenta años más tarde, Eularia Serra y otras mujeres se quejarán ante las autoridades de ser molestadas por las cofradias de percheros, terciopeleros y veleros de la ciudad que estaban en contra de su actividad. Los consellers confirmaron y ampliaron la ordenanza anterior, el 16 de agosto de 1686, permitiéndoles seguir con su actividad y

«vendre o fer vendrer dites coses tant per la present ciutat $y$ en lo encant publich $y$ plassas publicas com tambe tenir y vendrer les sobredites coses en qualsevol part, aixi de las entradas de sas casas com altres parts y puestos axi dins armari com caxas teninlas ubertas o tancadas (sic) .... ${ }^{64}$

La prostitución es el trabajo femenino que mayor atencion suscita por parte de las autoridades municipales, pero no es contemplado por las mujeres que escribieron los libros de cuentas que estamos viendo por lo que, en esta ocasión, tampoco nos detendremos en él.

Como muestra final de la variedad de intereses que conforman la escritura privada propia de los libros de cuentas estos versos de Cervantes, anotados en el margen izquierdo del folio número dos del libro de Isabel Sala ${ }^{65}$, son un buen ejemplo:

62. El mostassaf era el funcionario público que debía velar para evitar el fraude en los pesos y medidas, garantizar la buena calidad de los productos que se vendían, la aplicación de los precios oficiales y el cumplimiento de las ordenanzas.

63. AHCB. Vol. 29, f. 78 r.

64. AHCB. Vol. 39, ff. 40v a 43 r.

65. ACA. Ms. 3401, f.2 r. 
«Es de vidrio la muger pero no se ha de provar si se puede o no quebrar porque todo podría ser.

Y es más fácil el quebrarse y no es cordura ponerse a peligro de romperse lo que no puede soldarse.

¿Quien mejorará mi suerte?

La muerte

¿Y el bien de amor quien le alcansa?

Mudanza

¿Y sus males quien los cura?

Locura

Desse modo no es cordura

querer curar la pasion

quando los remedios son

muerte, mudanza y locura» ${ }^{66}$.

La permanente dialéctica entre público y privado, clausura y mundo exterior, se refleja en los documentos, privados y públicos, que acabamos de ver. Las realidades que nos muestran hablan de la participación de las mujeres en el mundo más allá de los muros de sus casas, de su presencia activa en el interior y en el exterior, como vendedoras, artesanas, mendigas, asalariadas, gobernadoras de sus hogares y sus propiedades y, también, como mujeres de negocios. Las mismas que hacen préstamos, exigiendo unas garantías que podemos considerar abusivas, reparten limosnas y atienden a sus familiares y sirvientes. Sus libros nos dejan testimonio de las vidas que llegan y de las que se van. Compran y venden en nombre de terceros, gestionan capitales ajenos y preparan mermeladas. Lo que actualmente entendemos por público y privado no está tan alejado en la realidad de sus vidas como en la posterior concepción teórica de los espacios.

66. Id., Primera Parte, Capitulo 27, p. 260. 